\title{
Author Correction: Under-estimated wave contribution to coastal sea-level rise
}

\author{
Angélique Melet (1D, Benoit Meyssignac, Rafael Almar and Gonéri Le Cozannet
}

Correction to: Nature Climate Change https://doi.org/10.1038/s41558-018-0088-y, published online 26 February 2018.

In the version of this Article originally published, there were a number of errors in the main text, the Supplementary Information, the Methods and Figures that needed to be corrected as a result of a coding error when quantifying the wave contributions to sea level rise. In the 'Interannual-to-multidecadal changes' section of the main text, from the sentence beginning "Overall, the median..., ' $55 \%$ ' has been corrected to ' $58 \%$ '; in the following sentence, “This large contribution is globally evenly distributed..." has been adjusted to "This large contribution is distributed...', and '28\%' and ' $27 \%$ ' have been corrected to '38\%' and '20\%', respectively; and in the sentence following that, ' $39 \%$ ' and ' $16 \%$ ' have been corrected to '36\%' and ' $17 \%$ ', respectively. In the 'Sensitivity to the wave set-up and swash formulation.' section of the Methods, in equation (5), ' 0.756 ', ' 0.165 ' and ' 0.0368 ' have been corrected to ' 0.757 ', ' 0.167 ' and ' $0.044 H_{0}^{2}$ ', respectively; in the sentence beginning 'Wave contribution to...' ' $55 \%$ ' has been corrected to ' $28 \%$ '; the following sentence has been corrected to read: "On average, swell contribution to the total wave contribution are of $64 \%$ for all three formulations."; and in the final sentence, '(i) $(49 \%$ and $51 \% \ldots$. )' has been corrected to '(ii) $(41 \%$ and $59 \% \ldots)$ ', '(iii) $(36 \%$ and $64 \% \ldots$.$) ' has been corrected to '(i) (34 \%$ and $66 \% \ldots)$ ', and '(ii) (19\% and $81 \%$...)' has been corrected to '(iii) (25\% and $75 \%$...). In the 'Significance of the trends.' section of the Methods, in the final sentence '(Galápagos Islands, Callao, Clipperton Island and Tumaco)...' has been corrected to read '(Galápagos Islands and Tumaco)...' In the online versions of the article, Figs. 2-4 and Supplementary Figs 2-9 have been replaced to correct erroneous results that were the consequence of the coding error. All these figures are available as Supplementary Information to this correction notice.

Published online: 23 July 2018

https://doi.org/10.1038/s41558-018-0234-6

\section{Additional information}

Supplementary information is available for this paper at https://doi.org/10.1038/s41558-018-0234-6.

\section{Author Correction: Biological responses to the press and pulse of climate trends and extreme events}

R. M. B. Harris (D, L. J. Beaumont, T. R. Vance, C. R. Tozer, T. A. Remenyi, S. E. Perkins-Kirkpatrick, P. J. Mitchell, A. B. Nicotra, S. McGregor (D), N. R. Andrew (D), M. Letnic, M. R. Kearney, T. Wernberg (D) L. B. Hutley, L. E. Chambers, M.-S. Fletcher, M. R. Keatley, C. A. Woodward, G. Williamson, N. C. Duke (i) and D. M. J. S. Bowman (i)

Correction to: Nature Climate Change https://doi.org/10.1038/s41558-018-0187-9, published online 29 June 2018.

In the version of this Perspective originally published, affiliations 1 and 4 ware incorrect, and should have read: " 1 Antarctic Climate \&

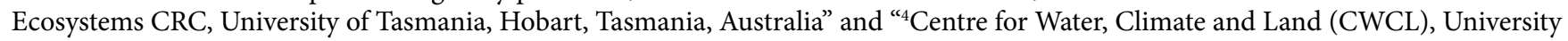
of Newcastle, Callaghan, NSW, Australia". These have been corrected in the online versions of this Perspective.

Published online: 11 July 2018

https://doi.org/10.1038/s41558-018-0237-3 